\title{
Antibody to serotype 8 rotavirus in Ecuadorian and German children
}

\author{
H. BRU்SSOW AND J. SIDOTI \\ Nestlé Research Centre, Nestec Ltd, Vers-chez-les Blanc, CH-1000 Lausanne 26, \\ Switzerland
}

(Accepted 18 August 1990)

\section{SUMMARY}

Only 2 out of 71 German patients infected with rotavirus $(3 \%)$ and 8 out of 147 German control patients $(5 \%)$ showed serum antibody to the new serotype 8 rotavirus. Such antibody was detected in the sera of 232 of 870 Ecuadorian children (27\%). Twelve Ecuadorian sera showed neutralizing activity only against serotype 8 and not to the other serotypes (1-4) tested, indicating that human serotype 8 rotavirus circulates in South America.

Rotavirus is a major cause of infectious gastroenteritis in children. Six serotypes of rotavirus have been identified in children : 1, 2, 3, 4, 8 and 9 [1]. The nucleotide sequence of the gene encoding the serotype-specific capsid glycoprotein, VP7, of all six human serotypes has been determined $[2,3]$. Gene sequencing defined nine regions of VP7 which are variable across rotavirus serotypes established by crossneutralization tests using animal hyperimmune sera. It is however still controversial whether antibody responses in children distinguish these six serotypes. Homotypic [4] and heterotypic [5-7] antibody responses have been reported after natural rotavirus infection. Up to now analysis has been restricted to serotypes 1, 2, 3 and 4 whose epidemiological importance has been established. In the present report we extend this analysis to serotype 8 rotaviruses, represented by rotavirus strain $69 \mathrm{M}$, which was isolated from an Indonesian child with gastroenteritis [8] and strain 678, which was isolated from a British calf with diarrhoea [9].

A population-based serum collection from Ecuadorian children obtained during a representative nutritional and health survey in Ecuador [10] and a hospitalbased serum collection from the University Children's Hospital at Bochum, West Germany (but excluding gastroenteritis patients) were screened for the presence of neutralizing antibody to serotype 8 rotavirus at a $1: 90$ serum dilution in the neutralization test described by Gerna and colleagues [11]. When the number of infected cells was reduced by $90 \%$ in comparison with virus-infected control cells the serum sample was said to be neutralizing. When the number of infected cells was only reduced by $50 \%$, the serum sample was said to be partially neutralizing. Both serum collections and the prevalence of neutralizing antibody to serotype 1-4 human rotavirus have been described previously $[12,13]$. 


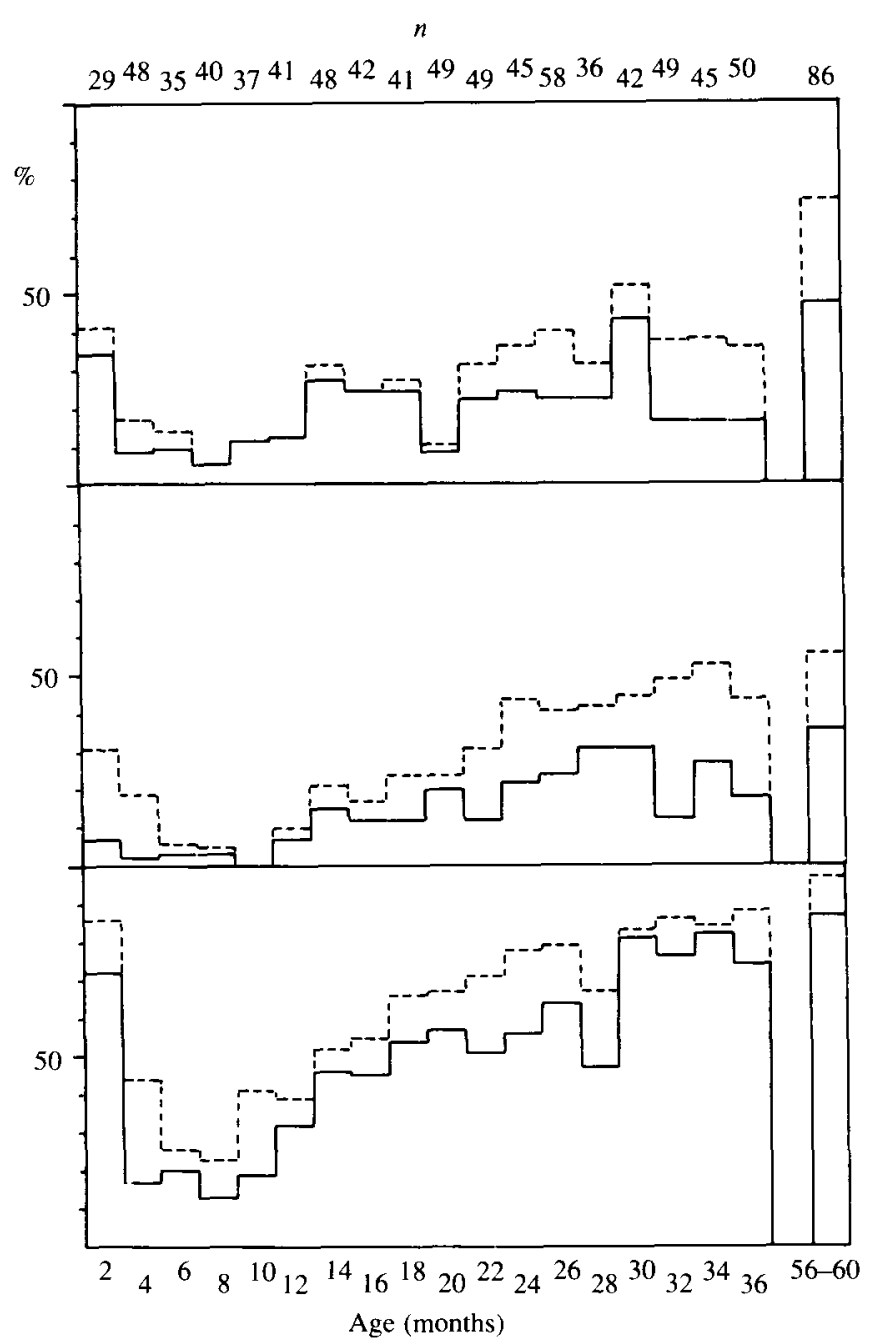

Fig. 1. Prevalence of neutralizing antibody to serotype 8 human rotavirus $69 \mathrm{M}$ (upper panel), serotype 8 bovine rotavirus 678 (middle panel) and, for comparison. serotype 4 human rotavirus Hochi (lower panel) in different age groups of Ecuadorian children. Age groups are indicated by the upper age limit in months: 2 means children $<2$ months of age, 4 means children $>2$ and $<4$ months of age etc. $n$ gives the number of children in each two-month age interval. Neutralization criterion was $50 \%(--)$ and $90 \%(-)$ reduction in the numbers of infected cells.

A total of $550(63 \%)$ of 870 sera from Ecuadorian children neutralized at least one of the four serotypes and 476 sera $(55 \%)$ neutralized human serotype 4 rotavirus [13]. Overall 190 out of 870 Ecuadorian sera tested $(22 \%)$ neutralized serotype 8 human rotavirus $69 \mathrm{M}$ and 149 sera $(17 \%)$ neutralized serotype 8 bovine rotavirus 678 . A total of 232 sera $(27 \%)$ neutralized at least one of these two serotype 8 rotaviruses: 107 sera neutralized both strains, whereas 83 and 42 sera neutralized only $69 \mathrm{M}$ or only 678 rotavirus, respectively. Figure 1 shows the agerelated prevalence of neutralizing antibody to human serotype 8 rotavirus $69 \mathrm{M}$ (upper panel) in comparison to antibody to bovine serotype 8 rotavirus 678 
(middle panel) and to antibody to human serotype 4 rotavirus Hochi (lower panel). Thirty-three per cent of the sera from infants up to 2 months old showed neutralizing antibody to rotavirus $69 \mathrm{M}$; this prevalence decreased to a minimum of $5 \%$ in the children 6-8 months old. In older children the prevalence increased slowly to reach $46 \%$ in 5 year old children.

It is clear that not all sera neutralized both strains of serotype 8 and this observation raises uncertainties over which was the original infecting strain. A serum sample which neutralizes serotype 8 rotavirus does, however, not necessarily reflect exposure to serotype 8 rotavirus. Cross-reacting antibodies could be induced by exposure to other rotavirus serotypes $[6,7]$. To study this point we analysed sera which neutralized serotype 8 human rotavirus $69 \mathrm{M}$ for their neutralizing capacity towards the four major human rotavirus serotypes (Table 1).

Eighty-one, 69, 48 and $87 \%$ of the 190 sera neutralizing serotype 8 human rotavirus $69 \mathrm{M}$ neutralized in addition human rotavirus serotypes $1,2,3$ and 4 respectively. Notably $41 \%$ also neutralized bovine rotavirus NCDV (serotype 6), whereas only 12 sera neutralized serotype 8 rotavirus $69 \mathrm{M}$ but none of the four major human rotavirus serotypes. In addition none of these 12 sera neutralized serotype 6 (NCDV) and serotype 10 (V1005, [9]) and only one serum neutralized serotype 9 (WI61) and another serum neutralized serotype 5 (OSU) rotavirus.

Figure 2 shows the age-related prevalence of neutralizing antibody to both serotype 8 rotavirus strains in the hospital-based serum collection from Bochum. Only 8 out of 147 children $(5 \%)$ between 8 and 48 months of age showed neutralizing antibody to human serotype 8 rotavirus in comparison with 66 children $(45 \%)$ who showed neutralizing antibody to serotype 4 rotavirus Hochi. Eleven and $82 \%$ of 45 maternal sera from Bochum showed neutralizing antibody to rotavirus $69 \mathrm{M}$ and Hochi, respectively.

Paired sera were collected from infants who had been admitted during the years 1986 and 1987 to the University Children's Hospital at Bochum with symptoms of acute gastroenteritis or from infants who developed acute gastroenteritis in the hospital. Twofold dilution series starting with a $1: 10$ serum dilution were used in the neutralization test described by Gerna and his colleagues [11]. Neutralization titres were the mean of three determinations. Acute and convalescent sera from 71 patients hospitalized with a serologically defined primary rotavirus gastroenteritis were studied for seroconversions : 42 children seroconverted to at least one human rotavirus serotype. Interestingly 28 of them seroconverted to two or three serotypes [6]. However only 2 out of the 71 rotavirus patients seroconverted to serotype 8 rotavirus $69 \mathrm{M}$ (patient 13 : titre increase from 10 to 70 ; patient 31 : titre increase from 10 to 70 ), but not to serotype 8 rotavirus 678 (all titres $<10$ ). Patient 13 showed also a titre increase to serotype 3 rotavirus $(10$ to 90$)$ and patient 31 to serotype 1 and 3 rotavirus (10 to 100 and 10 to 90 , respectively).

This low prevalence of neutralizing antibody to rotavirus $69 \mathrm{M}$ in both German serum collections suggests that German children recognize $69 \mathrm{M}$ rotavirus as different from the established rotavirus serotypes. This observation lends further support to the concept that human serotype 8 is distinct as established by animal hyperimmune sera $[8,14]$, gene sequencing $[2,3]$ and monoclonal antibodies $[15]$.

In contrast, the sera from the Ecuadorian children showed a substantially higher prevalence of neutralizing antibody to serotype 8 , although its prevalence 


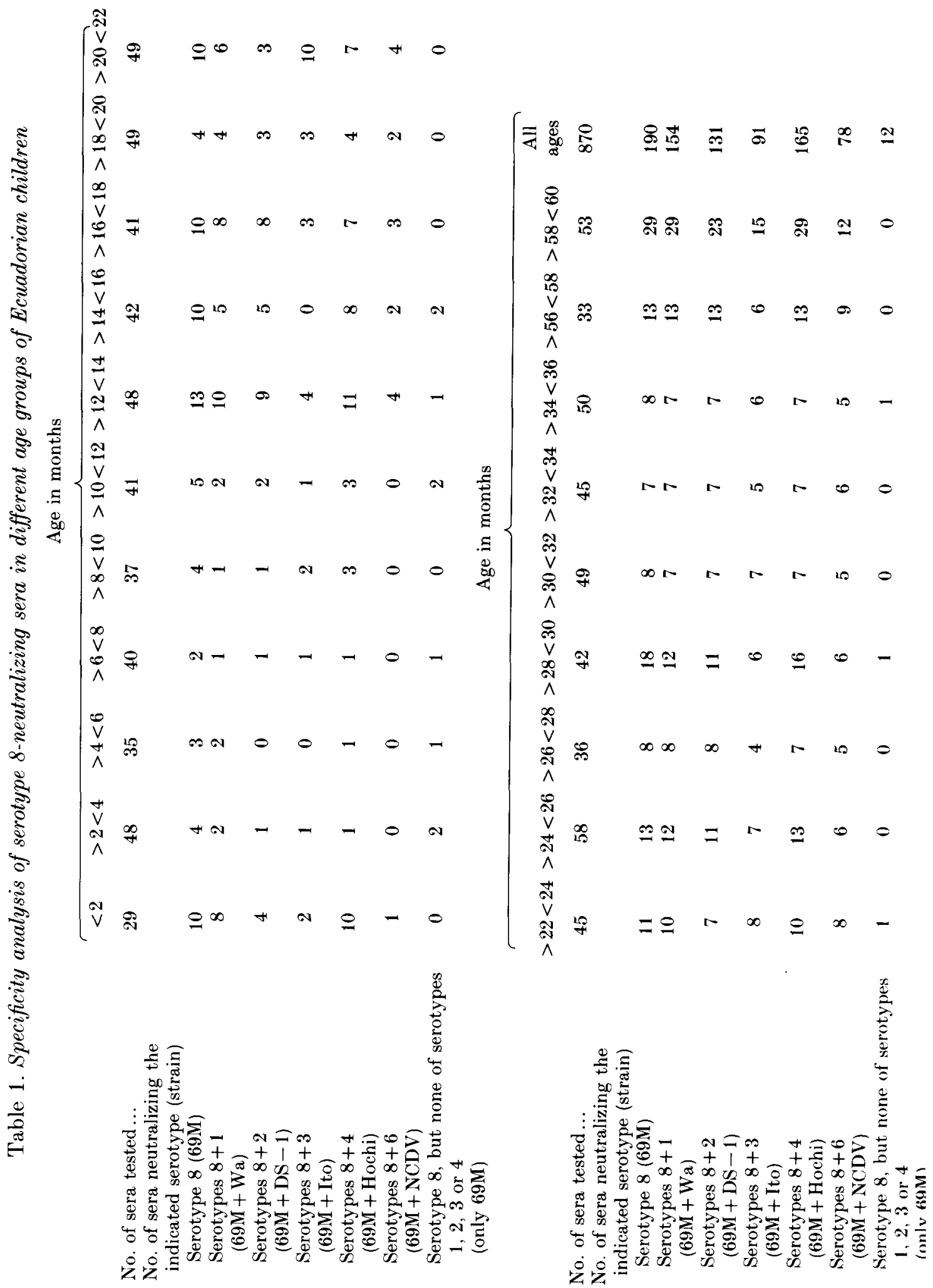




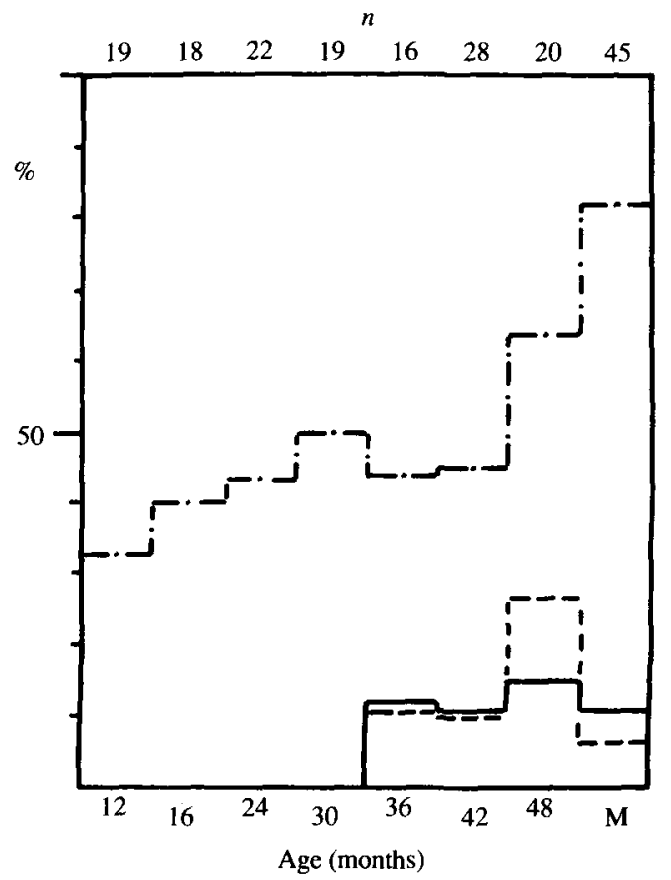

Fig. 2. Prevalence of neutralizing antibody to serotype 8 human rotavirus $69 \mathrm{M}$ (-), serotype 8 bovine rotavirus $678(--)$ and, for comparison, serotype 4 human rotavirus Hochi (-.-) in different age groups of 8-48 months old German children. Age groups are indicated by the upper age limit in months: 12 means children $>8$ and $<12$ months of age, 16 means children $>12$ and $<16$ months of age, etc. $n$ gives the number of children in each age interval. $M$ indicates maternal sera from German women.

is still lower than to any of the four established human rotavirus serotypes [13]. Except in Indonesia, the epidemiological importance of serotype 8 human rotavirus has not yet been investigated. In Ecuador we obtained sera which neutralized only serotype 8 rotavirus among those tested. This is seroepidemiological evidence that serotype 8 human rotavirus circulates in South America. Definitive proof must however await direct serotyping of rotavirus from stool samples with a serotype 8-specific monoclonal antibody [15]. Most of the sera which neutralize serotype 8 rotavirus, also neutralize three or four of the established rotavirus serotypes and $41 \%$ of these sera neutralize also serotype 6 bovine rotavirus NCDV, to which children are not known to be exposed under natural conditions [16]. Our tests therefore measured more the overall neutralization capacity of the sera than a serotype-specific immune response to serotype 8 rotavirus. The availability of monoclonal antibodies to serotype 8 rotavirus [15] might allow the development of a competitive binding immunoassay for detection of a serotype 8 -specific immune response $[17,18]$. This epitope-blocking immunoassay will give a more reliable analysis of serotype 8 -specific antibodies in children than the neutralization test. 


\section{ACKNOWLEDGEMENTS}

We thank Dr Snodgrass for sending us rotavirus strains 69M and 678, Drs Freire and Dirren for the Ecuadorian serum samples and Professors Werchau and Mietens for the German serum samples and Miss Jossevel for typing the manuscript.

\section{REFERENCES}

1. Estes MK, Cohen J. Rotavirus gene structure and function. Microbiol Rev 1989; 53: $410-49$.

2. Green KY, Hoshino Y, Ikegami N. Sequence analysis of the gene encoding the serotypespecific glycoprotein (VP7) of two new human rotavirus serotypes. Virology 1989; 168 : $429-33$.

3. Hum CP, Dyall-Smith ML, Holmes IH. The VP7 gene of a new G serotype of human rotavirus (B37) is similar to G3 proteins in the antigenic C region. Virology 1989; 170: $55-61$.

4. Zheng BJ, Han SX, Yan YK, et al. Development of neutralizing antibodies and group A common antibodies against natural infections with human rotavirus. J Clin Microbiol 1988; 26: $1506-12$.

5. Puerto FI, Padilla-Noriega L, Zamora-Chavez A, Briceno A, Puerto M, Arias CF. Prevalent patterns of serotype-specific seroconversion in Mexican children infected with rotavirus. J Clin Microbiol 1987; 25 : 960-3.

6. Brüssow $\mathrm{H}$, Werchau $\mathrm{H}$, Lerner L. et al. Seroconversion patterns to four human rotavirus serotypes in hospitalized infants with acute rotavirus gastroenteritis. J Infect Dis 1988; 158: $588-95$.

7. Gerna G, Sarasini A, Torsellini M, Torre D, Parea M, Battaglia M. Group- and type-specific serological response in infants and children with primary rotavirus infections and gastroenteritis caused by a strain of known serotype. J Infect Des 1990; 161 : 1105-11.

8. Matsuno S, Hasegawa A, Mukoyama A, Inouye $\mathrm{S}$. A candidate for a new serotype of human rotavirus. J Virol $1985 ; 54: 623-4$.

9. Snodgrass DR, Fitzgerald T, Campbell I, et al. Rotavirus serotypes 6 and 10 predominate in cattle. J Clin Microbiol $1990 ; 28: 504-7$.

10. Freire $\mathrm{W}$, Dirren $\mathrm{H}$, Mora JO, et al. Diagnóstico de la situación alimentaria, nutricional y de salud de la poplación ecuatoriana menor de cinco años (DANS). Consejo Nacional de Desarrollo, Quito 1988, Ministry of Public Health Publication.

11. Gerna G, Battaglia M, Milenesi G, Pasarini N, Percivalle E, Cattaneo E. Serotyping of cell culture-adapted subgroup 2 human rotavirus strains by neutralization. Infect Immun 1984; 43: 722-9.

12. Brüssow $\mathrm{H}$, Werchau $\mathrm{H}$, Liedtke $W$. et al. Prevalence of antibodies to rotavirus in different age-groups of infants in Bochum, West Germany. J Infect Dis 1988; 157: 1014-22.

13. Brüssow H, Sidoti J, Barclay D, Sotek J, Dirren H, Freire W. Prevalence and serotype specificity of rotavirus antibodies in different age groups of Ecuadorian infants. J. Infect Dis $1990 ; 162: 615-20$.

14. Albert MJ, Unicomb LE, Bishop RF. Cultivation and characterization of human rotaviruses with 'super short' RNA patterns. J Clin Microbiol 1987; $25: 183-5$.

15. Tursi JM, Albert MJ, Bishop RF. Production and characterization of neutralizing monoclonal antibody to a human rotavirus strain with a super-short RNA pattern. J Clin Microbiol 1987; $25: 2426-7$.

16. Ryder RW, Yolken RH, Reeves WC, Sack RB. Enzootic bovine rotavirus is not a source of infection in Panamanian cattle ranchers and their families. J Infect Dis 1986; 153 $1139-44$.

17. Shaw RD, Fong KJ, Losonsky GA, et al. Epitope-specific immune responses to rotavirus vaccination. Gastroenterol $1987 ; 93: 941-50$.

18. Green KY, Taniguchi K, Mackow ER, Kapikian AZ. Homotypic and heterotypic epitopespecific antibody responses in adult and infant rotavirus vaccinees : implication for vaccine development. J Infect Dis 1990; 161: 667-79. 